\title{
HEAD AND NECK
}

\section{Platysma myocutaneous flap revised in the free flaps era: clinical experience in 61 patients}

\author{
Tecnica alternativa per il prelievo del lembo di platisma miocutaneo nell'era dei lembi \\ liberi: esperienza clinica in 61 pazienti
}

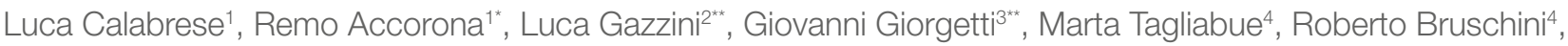 \\ Giacomo Pietrobon ${ }^{4}$, Mohssen Ansarin ${ }^{4}$ \\ ${ }^{1}$ Division of Otorhinolaryngology, "San Maurizio" Hospital, Bolzano, Italy; ${ }^{2}$ Department of Otorhinolaryngology and Head and Neck \\ Surgery, University Hospital of Verona, Italy; ${ }^{3}$ Department of Medicine, Surgery and Dentistry, University of Salerno, "Scuola Medica \\ Salernitana", Salerno, Italy; ${ }^{4}$ Division of Otorhinolaryngology and Head and Neck Surgery, European Institute of Oncology IRCCS, \\ Milan, Italy \\ 'Present address: Department of Otorhinolaryngology, Head and Neck Surgery, Fondazione IRCCS Ca' Granda, Ospedale Maggiore Policlinico, MIlano, Italy; \\ "Present address: Division of Otorhinolaryngology, "San Maurizio" Hospital, Bolzano, Italy
}

\section{SUMMARY}

Reconstruction of oral cavity and oropharyngeal defects following radical surgery for squamous cell carcinoma (SCC) can be achieved by a variety of options. In selected cases myocutaneous platysma flap (MPF) may be a valid choice. However, several anatomical and oncological controversies on the use of this flap are debated. A retrospective study on 61 patients treated between January 2005 and December 2017 in two referral centres in which MPF was used for the reconstruction of defects following surgical resection of SCC of the oral cavity and oropharynx was conducted. The technique of flap harvesting with anatomic details is described. In all cases the submental artery was sacrificed preserving the facial artery. All clinical data were collected. Tumours involved the oral cavity in $95.1 \%$ of cases, and the oropharynx in $4.9 \%$. Pathological staging (TNM $7^{\text {th }}$ edition) of tumours was: pT1 (42.6\%), pT2 (39.3\%), pT3 (4.9\%) and pT4a (13.1\%). Success rate of the flap was $93.4 \%$. Four $(6.5 \%)$ patients developed a partial necrosis of the skin paddle without platysma muscle involvement; none required surgical revision. The mean follow-up was 69 months (5153 months). Thirteen patients $(21.3 \%)$ developed a local recurrence, and in 1 patient was associated with contralateral neck metastasis. The MPF can be a suitable option in head and neck reconstruction of small or medium-sized defects in selected cases. The vascular pedicle can be provided by branches of the facial artery achieving both oncological radicality and optimal flap vascular supply.

KEY WORDS: platysma flap, myocutaneous flap, reconstructive surgery, oral cavity reconstruction

\section{RIASSUNTO}

La ricostruzione della cavità orale e dei difetti orofaringei a seguito di un intervento chirurgico radicale per carcinoma a cellule squamose (SCC) può essere ottenuta con varie opzioni. In alcuni casi selezionati il lembo miocutaneo di platisma (MPF) potrebbe essere una valida alternativa ai lembi liberi. Tuttavia, sono sorte negli anni numerose controversie anatomiche e oncologiche sull'uso di questo lembo. È stato condotto uno studio retrospettivo su 61 pazienti trattati tra gennaio 2005 e dicembre 2017 in due centri di riferimento, in cui è stata utilizzato il MPF per la ricostruzione dei difetti risultanti dalla resezione chirurgica di carcinomi squamosi della cavità orale e dell'orofaringe. Viene descritta la tecnica chirurgica di prelievo del lembo con particolare attenzione ai dettagli anatomici: in tutti i casi trattati l'arteria submentale veniva sacrificata preservando l'arteria facciale ed il peduncolo vascolare è stato basato su rami collaterali dell'arteria stessa. Le neoplasie coinvolgevano la cavità orale nel 95,1\% dei casi e l'orofaringe nel 4,9\%. La stadiazione patologica (TNM 7 a edizione) dei tumori era: pT1 (42,6\%), pT2 (39,3\%), pT3 (4,9\%) e pT4a (13,1\%). Il tasso di successo del lembo è stato del 93,4\%. Quattro $(6,5 \%)$ pazienti hanno sviluppato una necrosi parziale della padella cutanea senza coinvolgimento del pia-
Received: November 8, 2019

Accepted: November 22, 2019

Correspondence

Luca Gazzini

Department of Otorhinolaryngology and Head and Neck Surgery, University Hospital of Verona, piazzale Aristide Stefani 1, 37126 Verona, Italy

E-mail: lucagazzini100@gmail.com

Funding

None.

Conflict of interest

The Authors declare no conflict of interest.

How to cite this article: Calabrese L, Accorona R, Gazzini L, et al. Platysma myocutaneous flap revised in the free flaps era: clinical experience in 61 patients. Acta Otorhinolaryngol Ital 2020;40:173-180. https://doi. org/10.14639/0392-100X-N0538

(c) Società Italiana di Otorinolaringoiatria e Chirurgia Cervico-Facciale

\section{cc)(1) $(9$}

This is an open access article distributed in accordance with the CC-BY-NC-ND (Creative Commons Attribution-NonCommercial-NoDerivatives 4.0 International) license. The article can be used by giving appropriate credit and mentioning the license, but only for non-commercial purposes and only in the original version. For further information: https:// creativecommons.org/licenses/by-nc-nd/4.0/deed.en 
no muscolare del platisma; in nessun caso si è resa necessaria una revisione chirurgica del lembo. Il follow-up medio è stato di 69 mesi (5-153 mesi). Tredici pazienti (21,3\%) hanno sviluppato una recidiva locale, in 1 paziente questa era associata alla presenza di una metastasi del collo controlaterale. L'MPF può essere un'alternativa nella ricostruzione di difetti di piccole o medie dimensioni della testa e del collo in casi selezionati. Il peduncolo vascolare può essere fornito da rami dell'arteria facciale, raggiungendo così sia una corretta radicalità oncologica, sia un'ottimale vascolarizzazione del lembo.

PAROLE CHIAVE: lembo di platisma, lembo miocutaneo, chirurgia ricostruttiva, ricostruzione del cavo orale

\section{Introduction}

Reconstruction of oral cavity defects following radical surgery for SCC can be achieved by a variety of techniques ${ }^{1-6}$. The choice is influenced by several factors, including size and location of the defect, patient characteristics, donor site morbidity, and functional and aesthetic outcomes ${ }^{1-13}$. Nowadays microvascular free flaps, for instance anterolateral tight (ALTFF) and radial forearm (RFFF), are considered the gold standard among head and neck surgeons for restoration of oral defects. However, in some particular situations, as in compromised patient in which a time-consuming procedure is at high risk, a pedicled flap could be a better choice ${ }^{9-13}$. Moreover, in small defects the donor site morbidity and aesthetic outcomes have to be taken into account ${ }^{2,4}$. Many loco-regional pedicle flaps are available for head and neck reconstruction ${ }^{9-15}$; among these, the MPF presents some advantages, for instance appropriate thickness, ideal pliability, wide arch of rotation (almost $180^{\circ}$ ), and good colour match with facial skin in case of external reconstruction. Furthermore, donor site morbidity is low, and it is easy to access in the same operative field, reducing the operation time ${ }^{1-5}$. Consequently, MPF can be an excellent choice in reconstruction of oral cavity, oropharynx, and low face defects of small to medium size $\left(15-75 \mathrm{~cm}^{2}\right)^{1-8}$; however, some anatomical and oncological controversies on the use of this flap are still debated. In particular, several authors have stated that it is difficult to perform a safe oncological neck dissection and at the same time preserve effective vascularisation of the flap ${ }^{7-12}$.

The aim of this paper is to analyse the use of MPF for reconstruction of post-surgical defects in 61 cases of oral cavity and oropharyngeal tumours. A detailed technique of flap harvesting is described step-by-step. Additionally, the main indication and controversies reported in the literature, are critically analysed.

\section{Materials and methods}

A retrospective review on all patients in which a MPF was used for reconstruction of defects following surgical resection in oral cavity and oropharynx, between January 2005 and December 2017, was conducted at the Head and Neck Surgery Department of the European Institute of Oncology
(Milano) and at the Division of Otorhinolaryngology of "San Maurizio" Hospital (Bolzano).

Inclusion criteria was:

- affected by SCC of the oral cavity or oropharynx.

Exclusion criteria were:

- submitted to prior surgery with neck dissection;

- submitted to prior radiation or chemoradiation therapy.

The surgical technique was standardised for the entire series of patients. Demographic data, risk factors and tumour characteristics were collected.

Intraoperative data were type of surgical approach (pull through, mandibulotomy, mandibulectomy), need for monolateral or bilateral neck dissection and intraoperative complications.

During follow-up, patients were evaluated daily until hospital discharge and with regular clinical controls during longterm follow-up. Data on total hospital stay, local postoperative complications (diastasis, fistula, and partial or total necrosis), adjuvant therapies and disease progression were reported.

The clinical pathological staging of the disease was performed according to the $7^{\text {th }}$ edition of the AJCC/UICC TNM and clinical staging system.

\section{Surgical indications}

This flap was chosen in patients with the subsequent characteristics:

- defect in oral cavity and oropharynx (without indication for compartmental surgery) that could not be closed by a primary suture, up to $75 \mathrm{~cm}^{2}$;

- need for neck dissection;

- compromised patients that could not bear the longer length of general anaesthesia required for a free flap (i.e. American Society of Anaesthesiologists [ASA] physical status classification class 3 or 4, poorly controlled diabetes mellitus or hypertension, chronic obstructive pulmonary disease [COPD], morbid obesity body mass index $>40$, moderate or severe reduction of cardiac ejection fraction, implanted pacemaker, end stage renal disease [ESRD] undergoing dialysis, recent history of myocardial infarction, coronary stents, transient ischemic attach [TIA] or stroke).

\section{Surgical technique}

The surgical technique of MPF harvesting is well described 
in the literature. In the present study, we describe a modified technique to harvest the superiorly based MPF, developed by the senior authors. The vascular support of the flap, in this variant, is not provided by the submental artery as usually described in the literature. Conversely, it is ensured by constant branches of the facial artery anastomosed in the paramandibular area with the orbicular artery system. We point out several technical details in flap elevation and its insetting.

Surgical steps

Step \#1

A U-shaped flap is drawn including a skin island centred on the lower portion of the platysma muscle just above the clavicular insertion. An adequate length of the horizontal axis of the skin paddle is required to close the donor site with minimal tension (Fig. 1A).

Step \#2

Sharp dissection of the flap is conducted in a subcutaneous plane until the level of the hyoid bone. The clavicular insertions of the platysma muscle are divided and the muscle with the overlying skin island is elevated. The external jugular vein is ligated and harvested with the flap, while the portion of the external cervical fascia overlying the sternocleidomastoid muscle is not included (Fig. 1B, 1C).

\section{Step \#3}

The elevation of the flap is then conducted toward the mandible dividing the segmental vessels of the middle part of the muscle. A key point of this surgical step is to identify and preserve the marginal branch of the facial nerve. Any perforator skin vessel arising from the cranial portion has to be preserved to ensure adequate vascularisation of the distal part of the flap and minimise the risk of skin necrosis. The perforators are located in the adipofascial tissue; therefore, the dissection should be conducted in a deeper plane to preserve these vessels. After this step, platysma muscle is dissected anteriorly and posteriorly to achieve full mobilisation of the flap (Fig. 1D).

\section{Step \#4}

Submandibular gland dissection allows identification and preservation of the common trunk of the facial artery while all the cervical branches, including the submental artery, are ligated during level IA dissection ensuring oncological radicality. This is the key point of the whole surgical procedure, because in the present technique the vascular arterial supply of the flap is provided by small calibre constant branches of the facial artery that are routinely identified in the submandibular area. These branches are direct to platysma and anastomosed in the paramandibular area with the orbicular artery system and not from the submental artery as widely described in literature (Fig. 2). This step is contraindicated if massive metastases at level IB are present. Neck dissection, either radical or selective, is then completed (Fig. 1E). If possible, the facial vein is preserved.

\section{Step \#5}

After tumour resection in pull-through or mandibulotomy, the defect is reconstructed rotating the MPF into the oral cavity. Any twisting, excessive traction, or stretching against the inferior edge of the mandible should be avoided. Moreover, the tunnel should be of adequate width in order to avoid vascular supply impairment. During the flap insetting, the sutures at the proximal aspect of the flap have to be cutaneous only, without involving the subcutaneous and muscular layers, in order to maximise blood flow through the muscle pedicle to the skin paddle.

\section{Step \#6}

The neck donor site is than closed primarily, usually without tension (Fig. 1F).

\section{Results}

A total of 61 patients, 37 men $(60.6 \%)$ and 24 women (39.4\%), matched the inclusion criteria and were analysed in the present study. Median age was 68 years (25-87). Table I summarises the demographic data and patient characteristics. In the large majority of cases the disease involved the oral cavity with 58 (95.1\%) cases, while only 3 (4.9\%) patients presented oropharyngeal cancer fit for MPF reconstruction. Regarding subsites, in the oral cavity 29 (47.95\%) patients presented with oral floor SCC, $15(24.6 \%)$ with cheek mucosa SCC, 10 (16.14\%) with gum SCC, 2 (3.3\%) with lateral border of the tongue SCC, and 2 (3.3\%) with retromolar trigone SCC: concerning oropharyngeal SCC, all the 3 (4.9\%) patients presented with lateral wall SCC. Pathological staging of the tumour was: pT1 in 26

Table I. Preoperative characteristics of patients treated with radical surgery followed by reconstruction with platysma $(n=61)$.

\begin{tabular}{lc} 
Characteristics & $\mathbf{N}(\%)$ \\
Age (years) & \\
Median (range) & $68(25-87)$ \\
Gender & \\
Male & $37(60.6)$ \\
Female & $24(39.4)$ \\
Alcohol consumption & \\
No & $20(32.8)$ \\
Yes & $40(65.6)$ \\
Former & $1(1.6)$ \\
Smoking & \\
No & $16(26.2)$ \\
Yes & $29(47.5)$ \\
Former & $16(26.3)$ \\
\hline
\end{tabular}



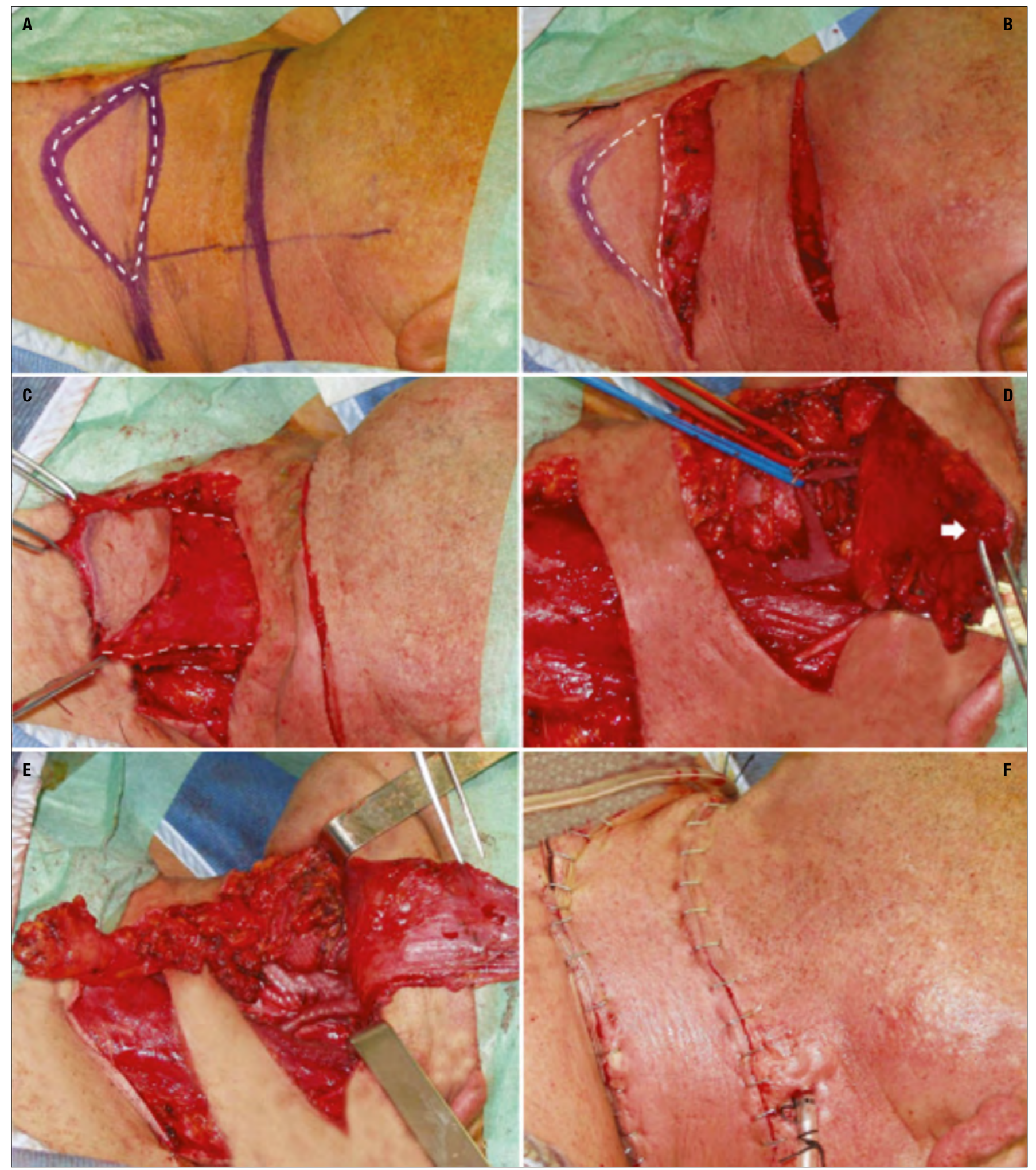

Figure 1. Surgical steps. Panel a: Drawing of the flap. Dotted line: Skin paddle of the platysma myocutaneous flap. Panel b: Cervical incision and identification of the platysma muscle. Dotted line: skin paddle of the platysma myocutaneous flap. Panel c: Harvesting of the platysma myocutaneous flap detaching it from the deep dissection plane. Dotted line: anterior and posterior limit of the incision of the platysma muscle. Panel d: Identification of the facial artery (red vessel loop) and vein (blue vessel loop). White arrow: platysma myocutaneous flap rotated in order to expose the submandibular region. Panel e: Neck dissection of level I is completed by preserving the facial vessels and sacrificing the submental pedicle. Panel $\mathrm{f}$ : Closure of the neck incision and the skin donor site. 


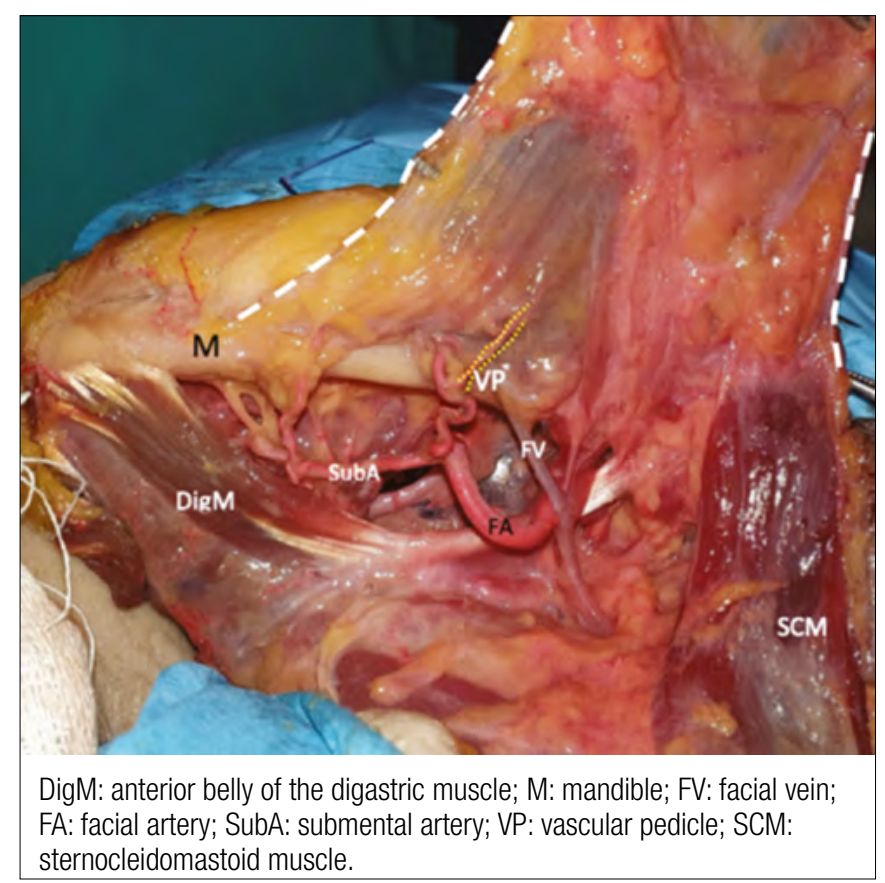

Figure 2. Anatomy of the submandibular region and vascularisation of the platysma myocutaneous flap. Vascular pedicle of the flap arising from the facial artery in submandibular area and direct to the platysma muscle. (yellow dotted line). White dotted line: anterior limit of the platysma muscle.

cases $(42.6 \%)$, pT2 in $24(39.3 \%)$, pT3 in $3(4.9 \%)$, and pT4a in 8 cases $(13.1 \%)$. Moreover, the pathological staging of the neck was: $\mathrm{pN} 0$ in 38 cases $(62.2 \%)$, pN1 in 13 cases (21.3\%), pN2 in 10 cases (16.4\%), and pN3 in none. Level IB was involved by lymph node metastasis in $5(8.2 \%)$ patients at pathological examination. In 59 of 61 patients, tumourfree margins (R0) were achieved, while in the remaining 2 patients, microscopic positive margins (R1) were found.

The surgical approach consisted in pull through procedure in $43(70.5 \%)$ cases, mandibulotomy in $15(24.6 \%)$ cases, and mandibulectomy in $3(4.9 \%)$ cases (Tab. II).

The mean hospitalisation time was 14 days (2-28 days) with a mean discharge time of 12 days after surgery. All patients were able to start oral feeding before they were discharged.

Regarding local early post-operative complications, flap failure or other major complications did not occur in any case. Nevertheless, 4 patients developed a necrosis of the skin paddle without impairment of the flap because the underlying platysma muscle remained vital; the skin necrosis was managed with daily bedside debridement achieving healing by second intention. Among these, 1 patient developed diastasis of the wound and 1 a salivary fistula, both treated successfully conservatively.

Adjuvant treatment was required in 17 (27.8\%) patients: $4(6.5 \%)$ patients received concomitant chemoradiation
Table II. Patient and tumour characteristics after surgery $(n=61)$.

\begin{tabular}{|c|c|}
\hline Characteristics & $\mathrm{N}(\%)$ \\
\hline $\begin{array}{l}\text { Type of surgery on tumour } \\
\text { Mandibulectomy } \\
\text { Mandibulotomy } \\
\text { Pull through }\end{array}$ & $\begin{array}{c}3(4.9) \\
15(24.6) \\
43(70.5)\end{array}$ \\
\hline $\begin{array}{l}\text { Type of neck dissection } \\
\text { Monolateral } \\
\text { Bilateral }\end{array}$ & $\begin{array}{c}41(67.2) \\
20(3)\end{array}$ \\
\hline $\begin{array}{l}\text { Site of tumour } \\
\text { Gum } \\
\text { Tongue } \\
\text { Cheek mucosa } \\
\text { Retromolar trigone } \\
\text { AGP }\end{array}$ & $\begin{aligned} 2 & (3.3) \\
22 & (36.1) \\
10 & (16.3) \\
24 & (39.3) \\
3 & (4.9)\end{aligned}$ \\
\hline $\begin{array}{l}\text { Histology } \\
\text { Squamous cell carcinoma }\end{array}$ & $61(100)$ \\
\hline $\begin{array}{l}\text { Pathological status of tumour } \\
\text { T1 } \\
\text { T2 } \\
\text { T3 } \\
\text { T4a }\end{array}$ & $\begin{array}{c}26(42.6) \\
24(39.3) \\
3(4.9) \\
8(13.1)\end{array}$ \\
\hline $\begin{array}{l}\text { Pathological status of neck } \\
\text { N0 } \\
\text { N1 } \\
\text { N2 }(a, b, c) \\
\text { N3 }\end{array}$ & $\begin{array}{c}38(62.2) \\
13(21.3) \\
10(16.4) \\
0\end{array}$ \\
\hline $\begin{array}{l}\text { Grading } \\
\text { G1 } \\
\text { G2 } \\
\text { G3 } \\
\text { Not evaluable }\end{array}$ & $\begin{aligned} 12 & (19.7) \\
32 & (52.5) \\
17 & (60.7) \\
1 & (1.6)\end{aligned}$ \\
\hline $\begin{array}{l}\text { Defect dimension } \\
<25 \mathrm{~cm}^{2} \\
26-50 \mathrm{~cm}^{2} \\
>50 \mathrm{~cm}^{2}\end{array}$ & $\begin{array}{c}56(91.8) \\
4(6.6) \\
1(1.6)\end{array}$ \\
\hline
\end{tabular}

therapy, while $13(21.3 \%)$ radiation therapy alone. In none of these patient faliure or necrosis of the flap was observed. During long-term follow-up 12 (19.7\%) patients required local anaesthesia for a tongue synechia with ankyloglossia. Regarding the neck scar, none of the patients complained of impairment of neck movements or aesthetic dissatisfaction. The mean follow-up was 69 months (5-153 months). Twelve (19.7\%) patients developed a local recurrence, and in 1 patient the recurrence was associated with neck metastasis. All these patients were consequently surgically re-treated. Moreover, in $2(3.3 \%)$ cases the disease spread with distant metastasis. Finally, 8 (13.1\%) patients presented a second metachronous tumour at follow-up (Tab. III).

\section{Discussion}

The platysma is a thin quadrangular-shaped muscle that lies in the superficial fascia of the neck. The muscle fibres arise from the superficial fascia of the pectoralis 
Table III. Outcomes, adjuvant treatments, follow-up and failures ( $N=61)$.

\begin{tabular}{lc} 
Characteristics & N (\%) \\
Total hospital stay (days) & \\
Mean (range) & $14(2-28)$ \\
Post-surgery stay (days) & \\
Mean (range) & $12(2-27)$ \\
Local postoperative complications & \\
Yes & $6(9,8)$ \\
Partial skin necrosis (no reintervention) & 4 \\
Diastasis & 1 \\
Fistola & 1 \\
Debridement & \\
Yes & $12(19.7)$ \\
Adjuvant treatments & \\
None & $44(72.1)$ \\
Chemoradiotherapy & $4(6.5)$ \\
Radiotherapy & $13(21.3)$ \\
Follow-up & \\
Median (months) & 69 \\
Range (months) & $(5-153)$ \\
No evidence of disease & $44(72.1)$ \\
Alive with disease & $1(1.6)$ \\
Died of disease & $8(13.1)$ \\
Died of other tumour & $5(8.2)$ \\
Died for other causes & $3(4.9)$ \\
Failures & \\
Local & $13(21.3)$ \\
Locoregional & $1(1.6)$ \\
Distant metastasis & $2(3.3)$ \\
Second tumour & $8(13.1)$ \\
\hline &
\end{tabular}

major and deltoid muscles, cross the clavicle and run obliquely inserting at the angle of the mandible, inferior part of the cheek, and depressor muscles of the lip ${ }^{1-8,16-21}$. The main artery supplying the platysma is the submental branch of the facial artery ${ }^{3,4}$. Furthermore, other vessels provide blood supply to the muscle: branches of transverse cervical artery inferiorly, branches from occipital and posterior auricular arteries posteriorly and branches from superior thyroid artery anteriorly ${ }^{3,4}$. Venous drainage is ensured primarily by the external jugular vein, but it is also provided by the medial jugular veins, submental vein, facial vein, and anterior communicating veins ${ }^{3,4}$. Futrell was the first to describe a true muscular-cutaneous cervical flap composed of a lower cervical skin paddle and platysma muscle with the mandibular insertions preserved ${ }^{16}$, while other authors in the past described only random cervical platysma flaps ${ }^{22,23}$.

Considering the main vascular pedicle, two different variants of MPF can be harvested for head and neck reconstruction: the posterior flap based on branches of the occipital artery and the superior or vertical flap based on the submental branch of facial artery; the latter has the widest diffusion in surgical practice ${ }^{2-4}$. MPF has applications in reconstructing a large variety of head and neck defects and, in particular, has shown to be a good surgical option for the reconstruction of small to medium, and, rarely, large sized $\left(15-75 \mathrm{~cm}^{2}\right)$ mucosal defects of the oral cavity ${ }^{1-8,16-21}$. The thinness and pliability of the muscle-skin paddle unit make the platysma flap particularly suitable for tailoring defects of floor of the mouth, cheek mucosa, and gum to prevent post-operative functional impairment, due to primary closure with excessive tension ${ }^{1,2}$. According to the literature, other sites suitable for reconstruction with MPF are the lip, lateral wall of the oro-hypopharynx, and low facial skin defects ${ }^{1-8,16-21}$. When compared to other flaps such as the ALTFF, RFFF, and pectoralis major myocutaneous pedicle flap, the MPF is less bulky, with better skin colour match; the time for harvesting is shorter, and donor site morbidity is lower ${ }^{2,3}$. However, several anatomical and oncological controversies have limited its use ${ }^{1-8,16-21}$.

The first matter of debate regards blood supply of the flap. Indeed, the submental artery is usually ligated during neck dissection of submandibular area to achieve oncological radicality ${ }^{3-5}$. Several authors studied the anatomical vascular supply of the platysma muscle in relation to harvesting technique of MPF ${ }^{3}$. Some concluded that preserving the submental artery is not crucial to ensure survival of MPF ${ }^{3,17,22,23}$. This conclusion was supported by McGuirt et al. and Ruark et al. who first reported their experiences on 19 and 41 cases respectively, in which the anterior portion of facial artery was sacrificed without flap failure ${ }^{22,23}$. More recently, Huang et al. stated that submental artery preservation is not a critical step of flap harvesting, reporting a good surgical result in a study on 68 patients ${ }^{2}$. The hypothesis is that the vascularisation is converted to a random pattern after ligation of submental artery ${ }^{2,22,23}$. Indeed, the large number of anastomoses with the homolateral and contralateral lingual artery, inferior labial artery and superior thyroid artery, replace the submental artery, ensuring sufficient blood supply to the platysma ${ }^{1-3,22,23}$.

In the present study, resection of oral cavity tumours has been associated with an oncologically-safe neck dissection including levels IA and IB, sacrificing the submental artery. The main trunk of the facial artery was, conversely, preserved; in this way, the vascular supply of the flap is provided by branches of the facial artery anastomosed in the paramandibular area with the orbicular artery system, which is usually spared in a routine procedure of neck dissection. This is also supported by Cormak et al., who demonstrated the presence of small calibre vessels arising from the facial artery in the submandibular area, direct to platysma ${ }^{24-26}$. These findings were also observed in the present study: the branch of the facial artery providing the vascular supply to platysma was identified in all the flaps in this series. 
In addition, several authors reported that the mainstay of MPF success is preservation of an adequate venous drainage. Tension or kinking, especially when the flap is rotated under the mandible, in association with surgical closure of the main venous pedicle of the flap, can result in venous impairment with subsequent flap suffering and, in the worst hypothesis, failure ${ }^{4,5}$. For that reason, authors recommended to design the skin paddle at an adequate distance from the mandible to allow safe transfer of the flap into the oral cavity, with adequate rotation arch. Particular attention should be paid to include the external jugular vein in the deep surface of the flap ${ }^{1,2,4,24-26}$. Moreover, in N0 neck cases, the authors preserved the facial venous system in order to reduce the risk of venous complications.

Post-operative complication reported in the literature are highly variable, ranging from 0 to $45 \%{ }^{1-8}$. Huang et al., in a study on 68 patients, described $10(14.7 \%)$ events of flap venous congestion, among which 7 (10.3\%) suffered from partial necrosis of the flap; moreover, the authors reported $4(6 \%)$ cases of donor site dehiscence ${ }^{2}$. In a study by Koch et al. on 70 patients, $27 \%$ of cases developed a local complication, from partial to total necrosis of the flap, with $12 \%$ salivary fistula ${ }^{8}$. These extremely variable data are probably related to different harvesting techniques. In our experience, a MPF harvested with the technique described is highly reliable with a total flap survival rate of $93.4 \%$. In only 4 patients partial necrosis of the skin paddle was observed and the underlying platysma muscle remained viable in all cases. No major post-operative complication such as total necrosis of the flap were reported, and no patient required revision surgery.

Another very relevant issue is the oncological safety of MPF ${ }^{5}$. Some skills must be obtained during harvesting, since it has to be performed simultaneously with neck dissection. Indeed, it is oncologically unsafe to manipulate the lymphatic vessels during isolation of the vascular pedicle without performing lymph node dissection. Furthermore, the cervical fascia overlying the sternocleidomastoid muscle should be not included in the flap: in this way, flap elevation does not interfere with normal neck dissection.

In the present study, a median follow-up of 69 months (range 5-153 months) suggests that this reconstruction does not worsen long-term oncological results, which is consistent with the literature ${ }^{11}$. In fact, 13 patients reported local recurrence at the level of the primary tumour subsite (tongue, retromolar trigone, cheek mucosa), 1 patient developed a locoregional recurrence (contralateral lymphnodes relapse) and 2 patients had a distant metastasis relapse. Moreover, 8 patients developed a second tumour in a different subsite during follow-up. These latter cases are not related to treatment of the primary tumour, but con- versely, can be related to prolonged exposure of these patients to risk factors such as smoking and alcohol abuse, with consequent field cancerisation of the oral cavity and upper respiratory-digestive tracts.

In our opinion and according to the literature, the presence of positive lymph nodes is not a contraindication for the use of this flap ${ }^{4,5}$. The facial artery is normally preserved during routine neck dissection, while preservation of the submental artery is technically possible, but oncologically unsafe, especially in the case of tumours involving the floor of mouth or tongue. In our study, we found positive neck lymph nodes in 23 patients (pN1 in 13 cases, pN2 in 10 cases), and level IB was involved by lymph node metastasis in $5(8.2 \%)$ cases at pathological examination. Nevertheless, none of the patients in the present study developed a homolateral neck recurrence, and only one patient had a contralateral lymph node relapse at follow-up, demonstrating the oncological safety of this procedure in our series. Nonetheless, it is fundamental to highlight that this technique is contraindicated if massive infiltrative metastasis at level IB is present.

Regarding the neck scar, it does not usually affect neck movements; moreover, since it is very low in the neck, it is uncommon for patients to complain of aesthetic dissatisfication ${ }^{1-5,17}$.

Small skin paddle and thinness limit the use of MPF, especially when large resection or tongue compartmental surgery are required. Moreover, previous treatments such as surgery, radiotherapy and chemoradiotherapy are main contraindications for this flap ${ }^{3-8,17}$.

\section{Conclusions}

MPF is simple, versatile, and could be valued as a reconstructive alternative, with a low rate of complications. It is a good therapeutic option for reconstruction of the oral cavity and oropharynx with small- and medium-sized defects. The neck scar is not compromising from functional or aesthetic points of view.

The vascular supply of the MPF can be provided by specific branches of facial artery achieving both oncological radicality and a high flap success rate.

\section{References}

1 Bande C, Joshi A, Gawande M, et al. Utility of superiorly based platysma myocutaneous flap for reconstruction of intraoral surgical defects: our experience. Oral Maxillofac Surg 2018;22:45-51. https:// doi.org/10.1007/s10006-017-0665-7

2 Huang L, Gao X, Su T, et al. Vertical platysma myocutaneous flap reconstruction for oral defects using three different incision designs: experience with 68 cases. Int J Oral Maxillofac Surg 2018;47:324-9. https://doi.org/10.1016/j.ijom.2017.07.017 
3 Baur DA, Williams J, Alakaily X. The platysma myocutaneous flap. Oral Maxillofac Surg Clin North Am 2014;26:381-7. https://doi. org/10.1016/j.coms.2014.05.006

4 Eckardt AM. Platysma myocutaneous flap - its current role in reconstructive surgery of oral soft tissue defects. J Korean Assoc Oral Maxillofac Surg 2013;39:3-8. https://doi.org/10.5125/jkaoms.2013.39.1.3

5 Künzel J, Iro H, Psychogios G, et al. Closure of defects after resection of tumours of the oral cavity and the pharynx: medium- to longterm oncologic and functional results with the myocutaneous platysma flap. Eur Arch Otorhinolaryngol 2013;270:2537-45. https://doi. org/10.1007/s00405-013-2389-0

6 Khalid FA, Saleem M, Yousaf MA, et al. Oropharyngeal, hypopharyngeal and cervical esophageal reconstruction: an experience of pedicle flaps. J Coll Physicians Surg Pak 2019;29:168-72. https://doi. org/10.29271/jcpsp.2019.02.168

7 Lafont Rufat M, Nadal Cristobal B, Saura Fillat E, et al. Platysma flap: an alternative to free flaps. J Maxillofac Oral Surg 2014;13:84-6. https://doi.org/10.1007/s12663-013-0485-8

8 Koch M, Künzel J, Mantsopoulos K, et al. Defect closure after oral and pharyngeal tumour resection with the superiorly pedicled myocutaneous platysma flap: indications, technique, and complications. Eur Arch Otorhinolaryngol 2012;269:2111-9. https://doi.org/10.1007/ s00405-011-1891-5

9 Deganello A, Manciocco V, Dolivet G, et al. Infrahyoid fascio-myocutaneous flap as an alternative to free radial forearm flap in head and neck reconstruction. Head Neck 2007;29:285-91. https://doi. org/10.1002/hed.20512

10 Safdar J, Liu FY, Moosa Y, et al. Submental versus platysma flap for the reconstruction of complex facial defects following resection of head and neck tumours. Pak J Med Sci 2014;30:739-44. https://doi. org/ 10.12669/pjms.304.5177

11 Verbruggen C, Majoufre C, Derosamel L, et al. The horizontal myocutaneous infrahyoid island flap for soft-tissue head and oral reconstruction: step-by-step video description. Plast Reconstr Surg 2017;140:598e-600e. https://doi.org/10.1097/ PRS.0000000000003699

12 Chow TL, Kwan WWY, Fung SC, et al. Reconstruction with submental flap for aggressive orofacial cancer- an updated series. Am J Otolaryngol 2018;39:693-7. https://doi.org/10.1016/j.amjoto.2018.07.014

13 Lee RG, Baskin JZ. Improving outcomes of locoregional flaps: an emphasis on anatomy and basic science. Curr Opin Otolaryngol Head Neck Surg 2006;14:260-4. https://doi.org/10.1097/01. moo.0000233597.07047.6d

14 Giordano L, Di Santo D, Bondi S, et al. The supraclavicular artery island flap (SCAIF) in head and neck reconstruction: an Italian multiinstitutional experience. Acta Otorhinolaryngol Ital 2018;38:497-503. https://doi.org/10.14639/0392-100X-1794

15 Meccariello G, Montevecchi F. Defect-oriented reconstruction after transoral robotic surgery for oropharyngeal cancer: a case series and review of the literature. Acta Otorhinolaryngol Ital 2018;38:569-74. https://doi.org/10.14639/0392-100X-1473

16 Futrell JW, Johns ME, Edgerton MT, et al. Platysma myocutaneous flap for intraoral reconstruction. Am J Surg 1978;136:504-7. https:// doi.org/10.1016/0002-9610(78)90270-2

17 Tosco P, Garzino-Demo P, Ramieri G, et al. The platysma myocutaneous flap (PMF) for head and neck reconstruction: a retrospective and multicentric analysis of 91 T1-T2 patients. J Craniomaxillofac Surg 2012;40:e415-8. https://doi.org/10.1016/j.jcms.2012.02.015

18 Szudek J, Taylor SM. Systematic review of the platysma myocutaneous flap for head and neck reconstruction. Arch Otolaryngol Head Neck Surg 2007;133:655-61. https://doi.org/10.1001/archotol.133.7.655

19 Fang QG, Safdar J, Shi S, et al. Comparison studies of different flaps for reconstruction of buccal defects. J Craniofac Surg 2013;24:e4501. https://doi.org/10.1097/SCS.0b013e31828b7456

20 Mustafa el MA, Bhatia SK, Hammond DE. Platysma flap using dual skin paddles. Br J Oral Maxillofac Surg 2016;54:e59-60. https://doi. org/10.1016/j.bjoms.2016.02.017

21 Puxeddu R, Dennis S, Ferreli C, et al. Platysma myocutaneous flap for reconstruction of skin defects in the head and neck. Br J Oral Maxillofac Surg 2008;46:383-6. https://doi.org/10.1016/j. bjoms.2007.11.015

22 Ruark DS, McClairen WC Jr, Schlehaider UK, et al. Head and neck reconstruction using the platysma myocutaneous flap. Am J Surg 1993;165:713-9. https://doi.org/10.1016/s0002-9610(05)80794-9

23 McGuirt WF, Matthews BL, Brody JA, et al. Platysma myocutaneous flap: caveats reexamined. Laryngoscope 1991;101:1238-44. https:// doi.org/10.1288/00005537-199111000-00015

24 Cormack GC, Lamberty BG. Fasciocutaneous vessels. Their distribution on the trunk and limbs, and their clinical application in tissue transfer. Anat Clin 1984;6:121-31. https://doi.org/10.1007/ BF01773164

25 Cormack GC, Lamberty BG. A classification of fascio-cutaneous flaps according to their patterns of vascularisation. Br J Plast Surg 1984;37:80-7. https://doi.org/10.1016/0007-1226(84)90049-3

26 Cormack GC, Lamberty BG. Cadaver studies of correlation between vessel size and anatomical territory of cutaneous supply. Br J Plast Surg 1986;39:300-6. https://doi.org/10.1016/0007-1226(86)90038-X 